\title{
Inpatient Rehabilitation Care in Alberta: How Much Does Stroke Severity and Timing Matter?
}

\author{
Eric Tanlaka (i), Kathryn King-Shier, Theresa Green, Cydnee Seneviratne, \\ Sean Dukelow (iD
}

\begin{abstract}
Background: We examined the impact of stroke severity and timing to inpatient rehabilitation admission on length of stay (LOS), functional gains, and discharge destination. Methods: Alberta inpatient stroke rehabilitation data between April 2013 and March 2017 were analyzed. We evaluated the impact of stroke severity, as measured by the Functional Independence Measure (FIM), on timing to inpatient rehabilitation, functional gains, LOS, and discharge destination. Further, we examined whether timing to inpatient rehabilitation impacted the latter three factors. Results: The 2404 adults were subcategorized as mild (1237), moderate (1031), or severe (136) based on FIM at inpatient rehabilitation admission. Length of time to rehabilitation admission was not significantly $(p=0.232)$ different between stroke severities. Mean length of time (days) to rehabilitation admission was 19.79 (20.3 SD) for mild, 27.7 (35.7 SD) for moderate, and $37.70(56.8 \mathrm{SD})$ for severe stroke. Mean FIM change for mild $(M=16.3,9.9 \mathrm{SD})$ differed significantly $\left(\mathrm{p}=5.1 \times 10^{-9}\right)$ from moderate $(M=30.4,16.4 \mathrm{SD})$ and severe $(M=31.0,25.7 \mathrm{SD})$ stroke. The mean LOS for mild stroke $(M=41.3,31.9 \mathrm{SD})$ was significantly $\left(\mathrm{p}=5.1 \times 10^{-9}\right)$ different from moderate stroke $(M=86.8,76.4 \mathrm{SD})$ and severe stroke $(M=126.1,104.2 \mathrm{SD})$. Time to inpatient rehabilitation admission showed a small, significant impact on FIM change $\left(p=1.4 \times 10^{-9}\right.$, partial $\left.\eta^{2} 0.022\right)$ and LOS $\left(\mathrm{p}=1.1 \times 10^{-19}\right.$, partial $\eta^{2}$ 0.042). Shorter times to rehabilitation admission and mild stroke were associated with discharging home without needing homecare. Conclusion: Stroke severity has a significant impact on the conduct of inpatient rehabilitation. Yet, despite suggestions shortening timing to rehabilitation should improve outcomes, the impact on functional gains and rehabilitation LOS was small.
\end{abstract}

RÉSUMÉ: Les soins de réadaptation prodigués à des patients albertains hospitalisés: quelle est l'importance de la gravité des AVC et des délais d'admission en matière de réadaptation? Contexte: Nous nous sommes penchés sur l'impact que la gravité des AVC et les délais d'admission à des soins de réadaptation peuvent avoir sur la durée de séjour de patients hospitalisés, sur leurs gains fonctionnels et sur leur lieu de destination à la suite de leur congé. Méthodes: Nous avons analysé les données portant sur la réadaptation de patients albertains hospitalisés à la suite d'un AVC. Ces données couvraient la période allant d'avril 2013 à mars 2017. À l'aide de la mesure de l'indépendance fonctionnelle (MIF), nous avons ainsi évalué l'impact de la gravité des AVC sur les délais d'admission de patients hospitalisés à des soins de réadaptation, sur leurs gains fonctionnels, sur la durée de leur séjour et sur leur lieu de destination à la suite de leur congé. De plus, nous avons examiné dans quelle mesure les délais d'admission à des soins de réadaptation avaient un impact sur ces trois dernières variables. Résultats: Au total, 2404 adultes ont été répartis en trois catégories en fonction de leur résultat à la MIF: AVC légers (1237), modérés (1031) ou graves (136). Mentionnons que les délais avant d'être admis à des soins de réadaptation ne se sont pas révélés notablement différents $(\mathrm{p}=0,232)$ selon les niveaux de gravité des AVC. Les délais moyens (en jours) avant d'être admis à des soins de réadaptation ont été de 19,79 ( $\sigma 20,3)$ pour les AVC légers; de 27,7 ( $\sigma 35,7)$ pour les AVC modérés; et de 37,70 $(\sigma 56,8)$ pour les AVC graves. En se basant sur la MIF, les changements moyens pour les AVC légers $(M=16,3 ; \sigma 9,9)$ ont différé de façon notable $\left(\mathrm{p}=5,1 \times 10^{-9}\right)$ par rapport à ceux des AVC modérés $(\mathrm{M}=30,4 ; \sigma 16,4)$ et des AVC graves $(\mathrm{M}=31,0 ; \sigma 25,7)$. La durée moyenne de séjour dans le cas des AVC légers $(\mathrm{M}=41,3 ; \sigma 31,9)$ s'est par ailleurs révélée significativement $\left(\mathrm{p}=5,1 \times 10^{-9}\right)$ différente si on la compare aux autres catégories (AVC modérés $\mathrm{M}=86,8 ; \sigma 76,4$ ou $\mathrm{AVC}$ graves $\mathrm{M}=126,1 ; \sigma 104,2$ ). Les délais d'admission à des soins de réadaptation ont donné à voir un faible, quoique notable, impact sur les changements révélés par la MIF $\left(\mathrm{p}=1,4 \times 10^{-9}\right.$, eta-carré partiel $0,022)$ et sur la durée des séjours $\left(\mathrm{p}=1,1 \times 10^{-19}\right.$, eta-carré partiel 0,042$)$. Enfin, des délais d'admission plus courts à des soins de réadaptation et des $\mathrm{AVC}$ légers ont été associés, à la suite d'un congé, à un retour à la maison sans devoir recourir à des soins à domicile. Conclusion: La gravité des AVC a un impact considérable sur la réadaptation de patients ayant été hospitalisés. Bien qu'il ait été suggéré que la réduction des délais d'admission à des soins de réadaptation devrait améliorer l'évolution de leur état de santé, l'impact quant à leurs gains fonctionnels et leur durée de séjour en réadaptation a toutefois été mineur.

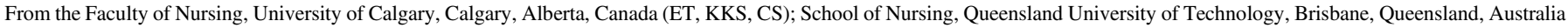
(TG); Department of Clinical Neurosciences, Division of Physical Medicine, Cumming School of Medicine, University of Calgary, Calgary, Alberta, Canada (SD)

Received April 30, 2019. Final Revisions Submitted July 22, 2019. Date of Acceptance July 31, 2019.

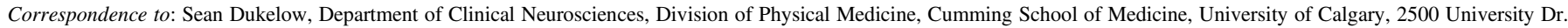
NW, Calgary, Alberta, Canada T2N 1N4. Email: spdukelo@ucalgary.ca 
Keywords: Stroke, Inpatient rehabilitation, Outcomes, Length of time waiting doi:10.1017/cjn.2019.276

\section{INTRODUCTION}

Stroke is the third leading cause of death and leading cause of adult disability in Canada. Approximately 50,000 Canadians and 4500 Albertans suffer a stroke each year with an annual mortality rate of $17.9 / 100,000$ individuals. ${ }^{1,2}$ Stroke costs the Canadian economy $\$ 3.6$ billion (\$200-\$300 million in Alberta) per year in direct and indirect medical expenses. ${ }^{1,2}$ Approximately 741,800 Canadian adults aged 20 or older $(25,000$ Albertans) are currently living with the effects of stroke, which may include physical, emotional, and behavioral problems that limit their ability to live independently and/or return to activities they once enjoyed. ${ }^{1}$

Thousands of stroke survivors access inpatient rehabilitation services across Canada annually. Stroke rehabilitation typically involves a patient working with a team, which has diverse expertise, that often includes nurses, physicians including neurologists and physiatrists, occupational therapists, physical therapists, speech and language pathologists, recreational therapists, social workers, and psychologists. The aim of rehabilitation is to optimize the functional and cognitive recovery of stroke patients and to increase their quality of life. About $20-30 \%$ of patients admitted to acute care hospitals for stroke are referred to rehabilitation units (located within the same facility as the acute care unit or in a different facility) following the acute stroke phase. In Canada, stroke patients are admitted to rehabilitation units in a median of 12 days from stroke onset with a median total admission Functional Independence Measure (FIM, measure of physical and cognitive disability with a focus on burden of care) score of 74 points for all stroke. ${ }^{3}$ Differences in FIM gain based on stroke severity have been reported previously in the literature. $^{4-6}$

In Canada, length of stay (LOS) in rehabilitation varies by stroke severity, with a median LOS of 31 days. ${ }^{3}$ In some studies, mild stroke patients experienced the shortest LOS, and severe stroke patients experienced the longest LOS. ${ }^{6-8}$ This variation may be attributed to the fact that patients with less severe stroke and/or medical comorbidities are likely to begin rehabilitation sooner and progress faster, resulting in a shorter LOS on a rehabilitation unit. Also, initiating rehabilitation early (prior to transfer to a rehabilitation unit) may give stroke patients a head start on entering a rehabilitation program and enable them to progress faster through rehabilitation. Additional stimulation from early rehabilitation may enhance blood flow to injured areas, promote clearance of toxins (e.g., free radicals), and stimulate healing and recovery, thus improving functional outcomes and shortening stroke patients' LOS in the rehabilitation unit. $^{8,9}$ The length of time stroke patients wait for inpatient rehabilitation may influence outcomes. Patients who are transferred sooner to a rehabilitation program may have improved functional outcomes. ${ }^{4-6,8,10-17}$ These outcomes have most often been measured by discharge FIM scores (motor and cognitive scores), Barthel Index (BI) scores, modified Rankin Scale (mRS) scores, and/or Rivermead Mobility Index (RMI) scores. Moderate and severe stroke patients who are admitted earlier to a rehabilitation unit have been shown to have larger motor and cognitive function gains. ${ }^{4,6,7}$ Patients admitted with moderate stroke have been found to experience greatest improvement in FIM scores when admitted 0-14 days post stroke compared to those with severe stroke, who experienced the worst FIM score changes when admitted 29-42 days post stroke. ${ }^{7}$ Based on these findings, investigators have suggested that patients admitted to a rehabilitation unit early have the greatest improvement in the ability to perform daily activities independently compared to those with delayed admission. Also, delaying admission to a rehabilitation unit for both moderate and severe stroke patients increases their likelihood of being transferred back to acute care. ${ }^{7}$

The analyses presented here provide a snapshot of inpatient stroke rehabilitation care in Alberta from 2013 to 2017. We evaluated differences in stroke rehabilitation outcomes (functional gains, LOS, discharge destination) based on stroke severity, given known differences in other provinces in Canada. ${ }^{18}$ Further, we wondered whether the time from acute care admission to inpatient rehabilitation admission had an influence on these same outcomes as suggested in the literature. We hypothesized that increased stroke severity would be related to larger functional gains, longer lengths of stay, and increased discharge to living environments that provided higher levels of assistance with daily activities. We also hypothesized that time spent waiting for entry to inpatient stroke rehabilitation care would lead to poorer outcomes.

\section{Methods \\ Research Design}

We conducted an analysis of primary data from a cohort of patients admitted to and discharged from inpatient stroke rehabilitation units in Alberta between April 2013 and March 2017. Data were obtained from the Alberta Health Services' stroke rehabilitation database. The study was approved by the University of Calgary's Conjoint Health Research Ethics Board (REB17-1186).

\section{Sample and Setting}

We included all clinically diagnosed cases of adult stroke (hemorrhagic or ischemic) with a documented inpatient rehabilitation unit stay in Alberta. In cases when the type of stroke at initial acute care presentation was ischemic and there was an eventual hemorrhagic component, we considered "hemorrhagic" as their stroke etiology. We excluded 321 cases from the original dataset provided by Alberta Health Services ( $n=2725$ cases) due to missing data (296); cases classified with a primary diagnosis of transient ischemic attack rather than stroke (15); or post-discharge living arrangements listed as boarding house (5), shelter (3), or public place (2). 


\section{Instruments}

The FIM was used to assess function at time of admission and discharge from the rehabilitation unit. FIMs were completed by rehabilitation unit staff at each of the nine centers providing data. Stroke severity was classified based on FIM admission scores. ${ }^{19}$ Scores of $<40$ were considered severe, 40-80 were considered moderate, and $>80$ were considered mild. ${ }^{20,21}$ The FIM has been tested for reliability, validity, responsiveness to change, feasibility for use, and meaningfulness in clinical settings when administered by trained and tested personnel. ${ }^{22}$ A ceiling effect on FIM scores for mild stroke patients (defined as the level at or above which a change in an independent variable no longer influences the FIM score) has been reported in the literature. ${ }^{23,24}$ We defined the ceiling effect as a FIM score of 126 at discharge from inpatient rehabilitation unit. We defined FIM change as the difference between total admission and discharge FIM scores. We defined FIM efficiency as the mean FIM change divided by the mean LOS in days. Other information collected from the Alberta Stroke Rehabilitation database included age, sex, patient's post-discharge living arrangement, LOS in rehabilitation units, and pre-admission comorbid conditions. The postdischarge living arrangements included home (private house or apartment) without health services, home with paid health services (home care/support), assisted living (including group home and supervised living setting), residential care (including long-term care facility, continuing care, convalescent, nursing home, and home for the aged), and acute care.

\section{Data Collection}

Data for the Alberta Stroke Rehabilitation Databases were assembled from Alberta Health Services Provincial Inpatient Discharge Abstract Database (DAD), National Rehabilitation System (NRS), and Calgary Rehabilitation Database and then transferred to the authors following appropriate ethics and administrative approvals.

\section{Data Analysis}

The mean, median, and standard deviation were calculated for continuous variables, and frequency distribution and percentages for categorical variables. Pearson correlations and standard multiple regression were used to examine relationships between variables. ANOVA was used to test main and interaction effects of the independent and dependent variables.

Chi-square tests were used to explore the relationship between days from acute care admission to inpatient rehabilitation admission and patients' post-discharge living arrangement. We also explored the relationship between categories of functional impairment and post-discharge living arrangements. Mann-Whitney U test was used to examine the mean difference in LOS and discharge motor/ cognitive FIM score of mild, moderate, and severe stroke patients.

\section{RESUlTS}

The sample consisted of 2404 male and female patients admitted to and discharged from inpatient stroke rehabilitation units in Alberta between April 2013 and March 2017 (see Table 1). These were clinically diagnosed cases of adult stroke (ischemic or hemorrhagic) subcategorized as mild, moderate, or severely impaired based on their initial FIM score at acute care admission.
Table 1: Demographic characteristics of study sample

\begin{tabular}{l|c|c|c|c}
\hline Characteristic & Total & Mild stroke & $\begin{array}{c}\text { Moderate } \\
\text { stroke }\end{array}$ & Severe stroke \\
\hline Age at acute care admission (years) & $67(58-77)$ & $71(61-82)$ & $72(60-84)$ \\
\hline Median (IQR) & $69(59-79)$ & 67 & 50.8 & 59.6 \\
\hline Sex, \% & 56.8 & 61.4 & 49.2 & 40.4 \\
\hline Male & 43.2 & 38.6 & 81.8 & 70.6 \\
\hline Female & 82.5 & 84.4 & 18.2 & 29.4 \\
\hline $\begin{array}{l}\text { Etiology of stroke, \% } \\
\text { Ischemic } \\
\text { stroke }\end{array}$ & 17.5 & 15.6 & & \\
\hline $\begin{array}{l}\text { Hemorrhagic } \\
\text { stroke }\end{array}$ & & & & \\
\hline
\end{tabular}

$\mathrm{IQR}=$ interquartile range.

The mean age of participants was 68 years (69 median; 13.9 SD). The mean LOS for active inpatient rehabilitation was 65.6 days (45 median; 65.9 SD), and the mean FIM change for all participants was 23.2 (21 median; 15.9 SD).

\section{Are Stroke Severity and Time Between Stroke Onset and Rehabilitation Admission Related?}

To better understand the impact of the time required to transfer to inpatient rehabilitation on functional outcomes, we first examined the relationship between the time since stroke (time from acute care admission to inpatient rehabilitation admission) and admission to rehabilitation FIM score (see Figure 1). The mean time since stroke (in days) to rehabilitation admission was 19.79 (20.3 SD) for mild stroke, 27.7 (35.7 SD) for moderate stroke, and 37.70 (56.8 SD) for severe stroke, with overall mean time since stroke of 24.20 (31.1 SD) days. We first examined the relationship between stroke severity and time since stroke using regression analyses with patients grouped in stroke severity subtypes. As expected, we observed the strongest relationship for individuals with mild stroke $\left(R^{2}=0.679 ; \mathrm{p}=1.6 \times 10^{-5}\right)$ with this group tending to demonstrate shorter times to inpatient rehabilitation admission and higher admission FIM scores (by definition), in general. The weakest relationship observed was for severe stroke $\left(R^{2}=0.267 ; \mathrm{p}=1.2 \times 10^{-162}\right)$. Similar findings were observed for the relationship between time since stroke to rehabilitation admission and motor FIM scores. However, relationships were not as strong for time since stroke and the cognitive FIM scores.

We wanted to determine whether time to inpatient rehabilitation was significantly different between the stroke severity groups. We first used a two-way between-groups analysis of variance. We observed no significant interaction between time since stroke and stroke severity $(\mathrm{F}(11,2384)=0.66, \mathrm{p}=0.777)$ so we examined for main effects. Not surprisingly, we observed a statistically significant main effect for stroke severity $\left(\mathrm{F}(2,2384)=916.26, \mathrm{p}=6.4 \times 10^{-296}\right)$ with a large effect size (partial $\eta^{2}=0.435$ ). However, we observed no main effect for time since stroke $(\mathrm{F}(6,2384)=1.35, \mathrm{p}=0.232)$, suggesting that time since stroke did not differ between stroke severities on admission to rehabilitation. Similar interaction and main effects on admission motor FIM scores were also observed when the aforementioned analysis was completed, with no main effect for 

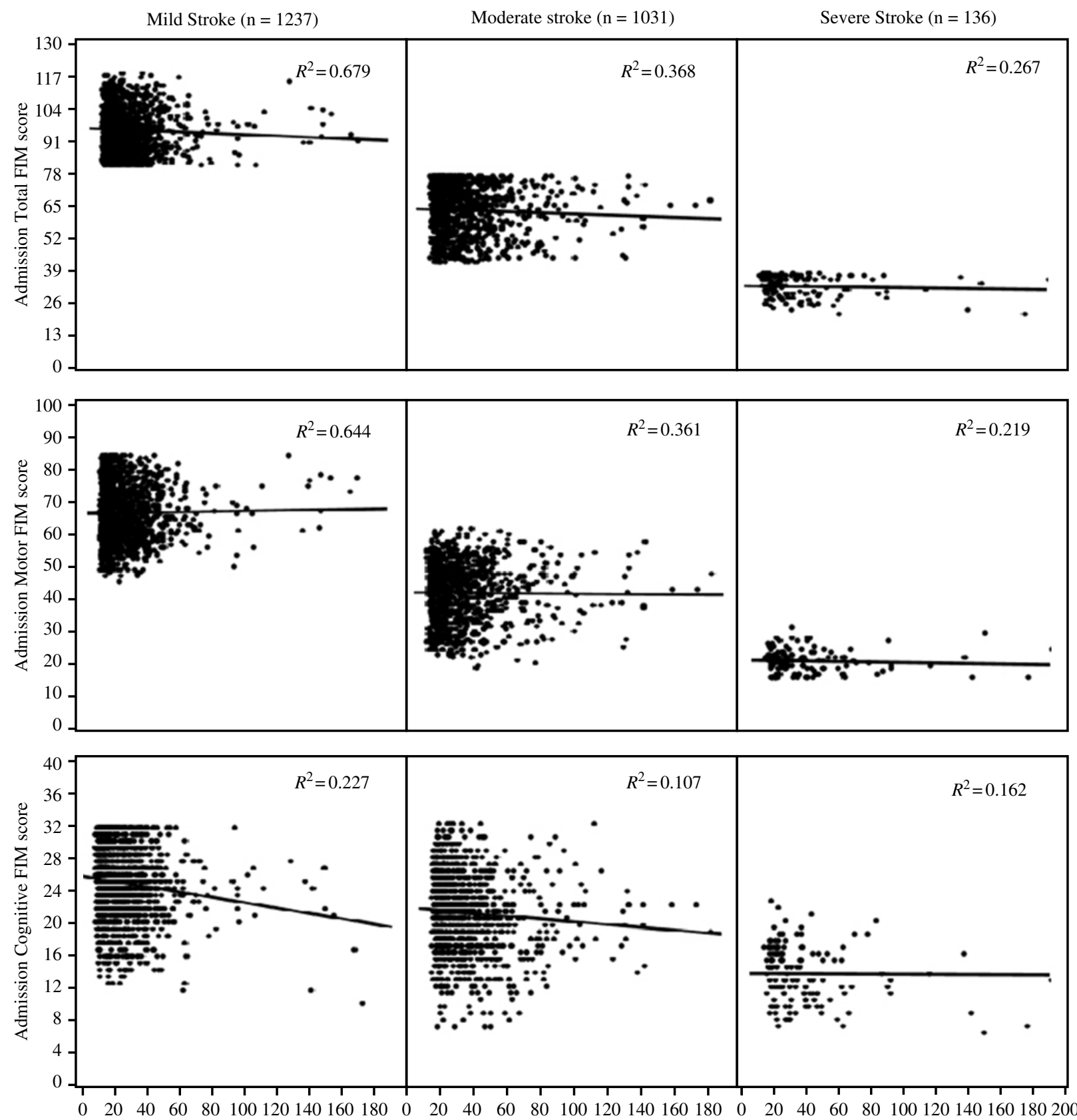

Days between acute care admission and inpatient rehabilitation admission

Figure 1: Scatter plots and trends illustrating relationships of functional scores at the time of admission and time to inpatient rehabilitation admission by impairment severity. The circles represent case numbers, and $R$-squared values $\left(R^{2}\right)$ represent the variance in functional scores caused by time to inpatient rehabilitation admission.

time since stroke $(\mathrm{F}(6,2384)=0.624, \mathrm{p}=0.711)$. The analysis was repeated again to examine time since stroke and admission cognitive FIM scores where main effects of stroke severity $\left(\mathrm{F}(2,2384)=100.66, \mathrm{p}=1.1 \times 10^{-42}\right)$ and time since stroke $\left(\mathrm{F}(6,2384)=4.31, \mathrm{p}=2.5 \times 10^{-4}\right)$ were found, although time since stroke demonstrated a small effect size (partial $\eta^{2}=0.011$ ).

\section{How Are Stroke Severity and Time Since Stroke Related to Functional Gains During Rehabilitation?}

We wished to determine whether time spent waiting for inpatient rehabilitation had a substantial impact on functional changes during rehabilitation. Mean FIM change during inpatient rehabilitation was 16.3 points for mild stroke (16 median; 9.9 SD), 30.4 points for moderate stroke (31 median; 16.4 SD), and 31.0 points for severe stroke (26 median; $25.7 \mathrm{SD}$ ), with a FIM efficiency of 0.4 for mild stroke, 0.3 for moderate stroke, and 0.2 for severe stroke. We conducted a regression analysis to examine the relationship between FIM change and time since stroke with patients grouped in stroke severity subtypes. The strongest relationship we observed was for mild stroke $\left(R^{2}=0.22 ; \mathrm{p}=1.1 \times 10^{-126}\right)$ (see Figure 2). Relationships for moderate $\left(R^{2}=0.17 ; \mathrm{p}=1.3 \times 10^{-94}\right)$ and severe $\left(R^{2}=0.02\right.$; 

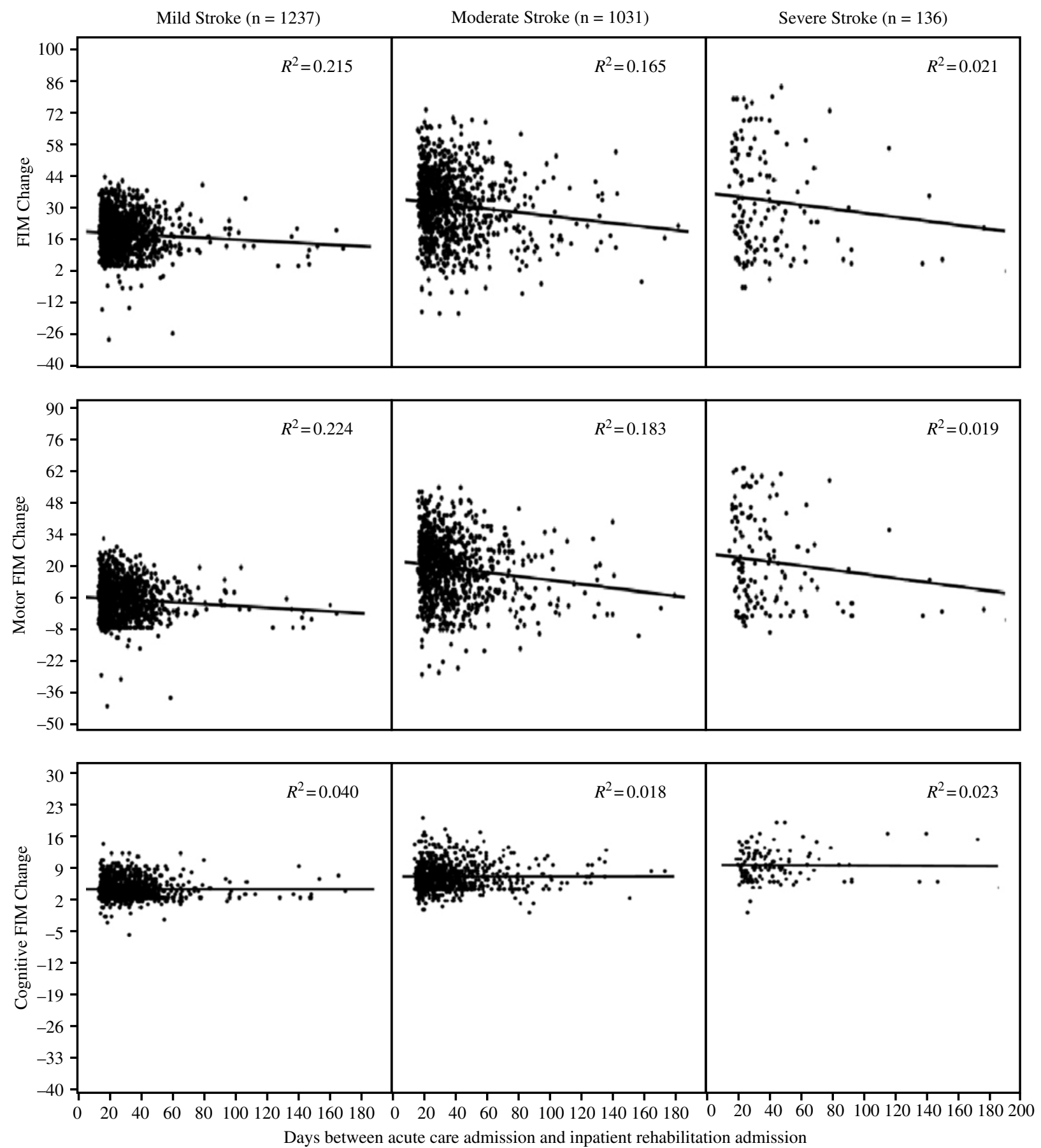

Figure 2: Scatter plots and trends illustrating relationships of functional changes and time to inpatient rehabilitation admission by impairment severity. The circles represent case numbers, and $R$-squared values $\left(R^{2}\right)$ represent the variance in functional changes caused by time to inpatient rehabilitation admission.

$\mathrm{p}=7.4 \times 10^{-12}$ ) stroke were weaker. For the motor FIM change, we observed the strongest relationship for individuals with mild stroke $\left(R^{2}=0.224 ; \mathrm{p}=3.0 \times 10^{133}\right)$. Relationships for moderate $\left(R^{2}=0.183 ; \mathrm{p}=5.2 \times 10^{-106}\right)$ and severe $\left(R^{2}=0.019\right.$; $\left.\mathrm{p}=1.6 \times 10^{-10}\right)$ stroke were also weaker. For the cognitive FIM change, we observed the strongest relationship for mild stroke $\left(R^{2}=0.040 ; \mathrm{p}=2.8 \times 10^{-22}\right)$ and the weakest relationship for moderate stroke $\left(R^{2}=0.018 ; \mathrm{p}=2.9 \times 10^{-10}\right)$.
Next, we wanted to determine whether FIM change was significantly different across stroke severities. Thus, we ran a two-way between-groups analysis of variance, which demonstrated an interaction effect of FIM change $(F(11,2384)=2.71$, $\mathrm{p}=0.002)$, a main effect for time since stroke $(\mathrm{F}(6,2384)$ $\left.=8.87, \mathrm{p}=1.4 \times 10^{-9}\right)$, and a main effect for stroke severity $\left(\mathrm{F}(2,2384)=61.41, \mathrm{p}=9.9 \times 10^{-27}\right)$. Post hoc comparisons using the Tukey HSD test indicated that the mean FIM change for mild 
stroke was significantly different from the mean FIM change for moderate stroke and severe stroke. The mean FIM change for moderate stroke patients did not differ significantly $(p=0.878)$ from the mean FIM change for severe stroke patients.

Similar interaction and main effects on motor FIM change were observed. Regarding effects on cognitive FIM change, the interaction effect was not statistically significant (F (11, $2384)=0.86, p=0.576)$. The main effect for stroke severity on cognitive FIM change $\left(\mathrm{F}(2,2384)=20.77, \mathrm{p}=1.1 \times 10^{-9}\right)$ was statistically significant with a small effect size (partial $\eta^{2}=0.017$ ), but the main effect for time since stroke $(F(6,2384)=1.43$, $\mathrm{p}=0.198$ ) was not statistically significant.

\section{Does Admission Stroke Severity Influence Rehabilitation Length of Stay?}

We examined the relationship between admission FIM score and LOS in rehabilitation. We began examining the relationship within the different stroke severities using regression analyses. Mean lengths of stay were 41.3 days (35 median; 31.9 SD) for mild stroke, 86.8 (64 median; 76.4 SD) for moderate stroke, and 126.1 (86.5 median; 104.2 SD) for severe stroke. We observed the strongest relationship between stroke severity and LOS for individuals with mild stroke $\left(R^{2}=0.696 ; \mathrm{p}=4.9 \times 10^{-34}\right)$ with this group tending to demonstrate shorter LOS in rehabilitation and higher admission FIM scores (by definition), in general (see Figure 3). The weakest relationship observed was for severe stroke $\left(R^{2}=0.367 ; \mathrm{p}=6.1 \times 10^{-239}\right)$. Similar findings were observed for motor FIM, but relationships were not as strong for the cognitive FIM scores.

To examine whether there were differences in LOS across stroke severity, we conducted a two-way between-groups analysis of variance. The interaction effect on admission FIM score ( $\mathrm{F}(9,2386)=2.93, \mathrm{p}=0.002)$, the main effect for LOS $\left(\mathrm{F}(6,2386)=6.77, \mathrm{p}=4.0 \times 10^{-7}\right)$, and the main effect for stroke severity $\left(\mathrm{F}(2,2386)=553.13, \mathrm{p}=4.3 \times 10^{-198}\right)$ were all statistically significant with small effect sizes for the interaction (partial $\eta^{2}=0.011$ ) and the main effects for LOS (partial $\eta^{2}=0.017$ ), and a large effect size for stroke severity (partial $\eta^{2}=0.317$ ). Post hoc comparisons using the Tukey HSD test indicated that the mean LOS for mild stroke was significantly $\left(p=5.1 \times 10^{-9}\right)$ different from the mean LOS for moderate stroke and severe stroke. The mean LOS for moderate stroke also differed significantly $\left(\mathrm{p}=5.1 \times 10^{-9}\right)$ from the mean LOS for severe group.

\section{Is Time Since Stroke to Rehabilitation Admission Associated With Length of Stay?}

We wished to determine whether time spent waiting for inpatient rehabilitation had a substantial impact on length of inpatient rehabilitation stay. Using regression analyses we explored the relationship between the time since stroke and LOS across the different stroke severity subtypes. We observed the strongest relationship for individuals with mild stroke $\left(R^{2}=0.180\right.$; $\mathrm{p}=3.2 \times 10^{-104}$ ) with this group tending to demonstrate shorter times to inpatient rehabilitation admission and shorter LOS. Relationships for moderate $\left(R^{2}=0.124 ; \mathrm{p}=5.6 \times 10^{-70}\right)$ and severe $\left(R^{2}=0.099 ; \mathrm{p}=7.4 \times 10^{-55}\right)$ stroke were weaker (see Figure 4$)$.

Also, we were interested in determining if there were significant differences in LOS across these groups based on time since stroke. Using a two-way between-groups analysis of variance, the interaction effect on $\operatorname{LOS}(\mathrm{F}(11,2384)=3.61$, $\left.\mathrm{p}=4.4 \times 10^{-5}\right)$, the main effect for time since stroke $\left(\mathrm{F}(6,2384)=17.30, \mathrm{p}=1.1 \times 10^{-19}\right)$, and the main effect for stroke severity $\left(\mathrm{F}(2,2384)=70.07, \mathrm{p}=2.7 \times 10^{-30}\right)$ were all statistically significant. However, effect sizes for the interaction (partial $\eta^{2}=0.016$ ) and the main effect on LOS for time since stroke (partial $\eta^{2}=0.042$ ) were small, but the effect size for the main effect on LOS for severity of stroke was medium (partial $\left.\eta^{2}=0.056\right)$.

\section{Is Time Since Stroke to Rehabilitation Admission Associated With Discharge Destination?}

To better understand the impact of the time required to get to inpatient rehabilitation on patient's post-discharge living arrangement, we analyzed and compared the different categories of post-discharge living arrangements. In general, those individuals who came to inpatient rehabilitation sooner were more likely to be discharged home without health services (see Figure 5). A chi-square test for independence indicated a statistically significant association between the time since stroke and post-discharge living arrangement, $\chi^{2}(24, n=2404)=153.59$, $\mathrm{p}=7.1 \times 10^{-21}$, Cramer's $v=0.13$, with a small effect size.

\section{Is Stroke Severity Associated With Discharge Destination?}

Finally, to determine whether stroke severity had a substantial influence on post-discharge living arrangement, we examined the relationship between stroke severity and post-discharge living arrangement (see Figure 6). We observed that individuals with mild stroke were more likely to be discharged to home without health services compared to those with severe stroke. Conversely, individuals with severe stroke were more likely to be discharged to residential care or back to acute care. Individuals with moderate stroke were more likely to be discharged to home with paid health services (homecare) compared to those with mild and severe stroke. A chi-square test for independence indicated a statistically significant association between stroke severity and post-discharge living arrangement, $\chi^{2}(8, n=2404)=517.53$, $\mathrm{p}=1.2 \times 10^{-106}$, Cramer's $v=0.33$, with a medium effect size.

\section{Is Etiology of Stroke Associated With Stroke Severity at Admission to Inpatient Rehabilitation?}

We wanted to determine whether patients' etiology of stroke impacted their stroke severity, so we examined the relationship between etiology of stroke and stroke severity. We observed that mild stroke patients were more likely to have ischemic stroke compared to moderate and severe stroke patients. Contrarily, severe stroke patients were more likely to have hemorrhagic stroke compared to mild and moderate stroke patients. A chisquare test for independence indicated a statistically significant association between etiology of stroke and stroke severity, $\chi^{2}$ $(2, n=2404)=16.83, \mathrm{p}=2.2 \times 10^{-4}$, Cramer's $v=0.084$, with a small effect size.

\section{Discussion}

\section{Summary Key Points}

We conducted a province-wide analysis of primary data from a large sample of patients admitted to and discharged from 

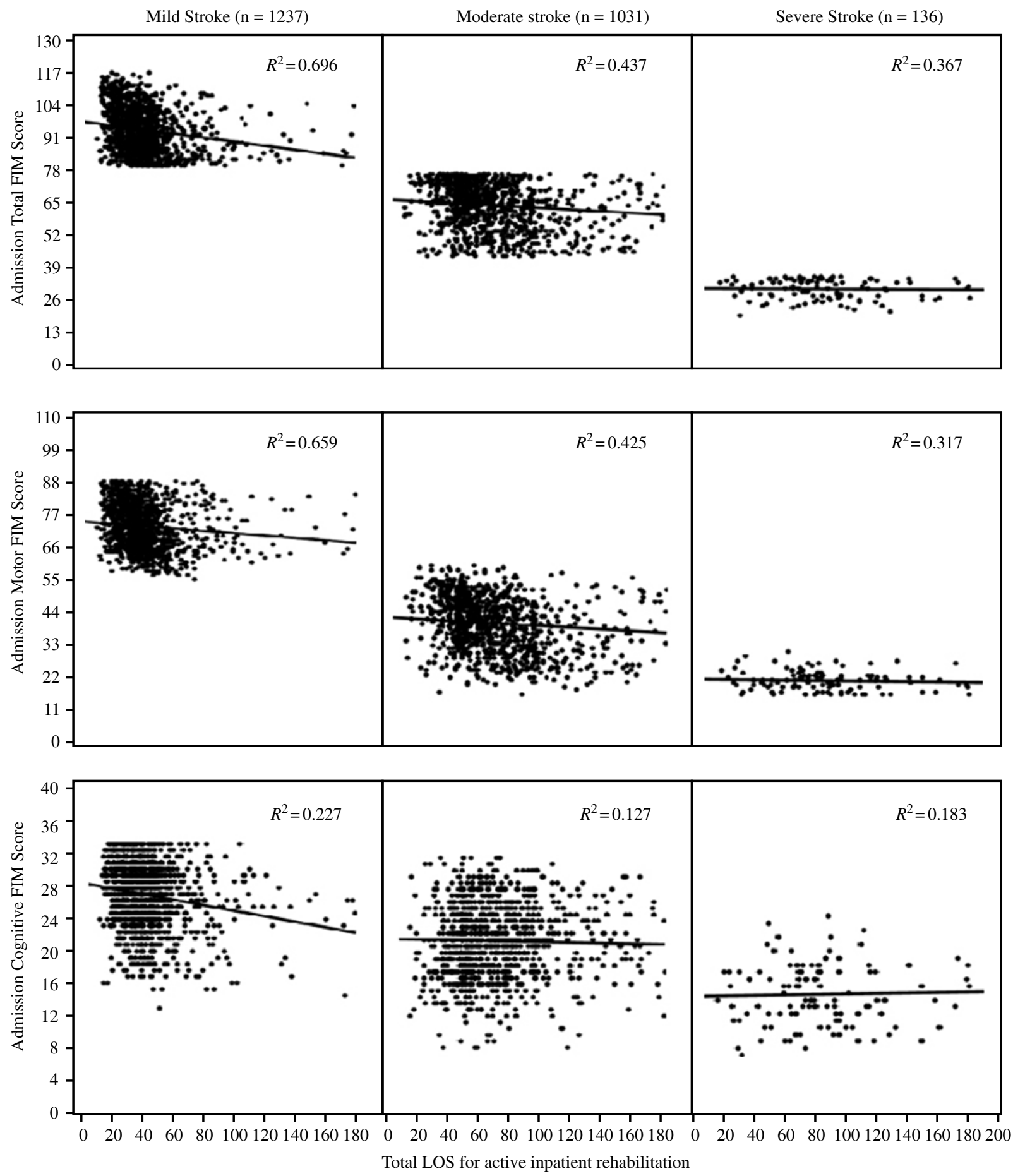

Figure 3: Scatter plots and trends illustrating relationships of functional scores at the time of admission and length of stay (LOS) in rehabilitation by impairment severity. The circles represent case numbers, and $R$-squared values $\left(R^{2}\right)$ represent the variance in functional scores caused by LOS in rehabilitation.

inpatient stroke rehabilitation units in Alberta between April 2013 and March 2017. Stroke severity was significantly related to functional gains in rehabilitation, LOS in rehabilitation, and discharge destination. Time since stroke had a small impact on LOS, and patients who gained entry later to inpatient stroke rehabilitation tended to be discharged to locations other than their home. The relationship between stroke severity and rehabilitation timing was more complicated and is discussed here.

\section{Comparison to the Rest of Canada}

We observed certain differences when comparing findings from this study to those reported from other Canadian provinces. With respect to the time since stroke, the overall mean time to rehabilitation unit admission was 24.2 days (mild stroke 19.8 days; moderate stroke 27.7 days; severe stroke 37.7 days). The overall mean time to rehabilitation admission was longer 


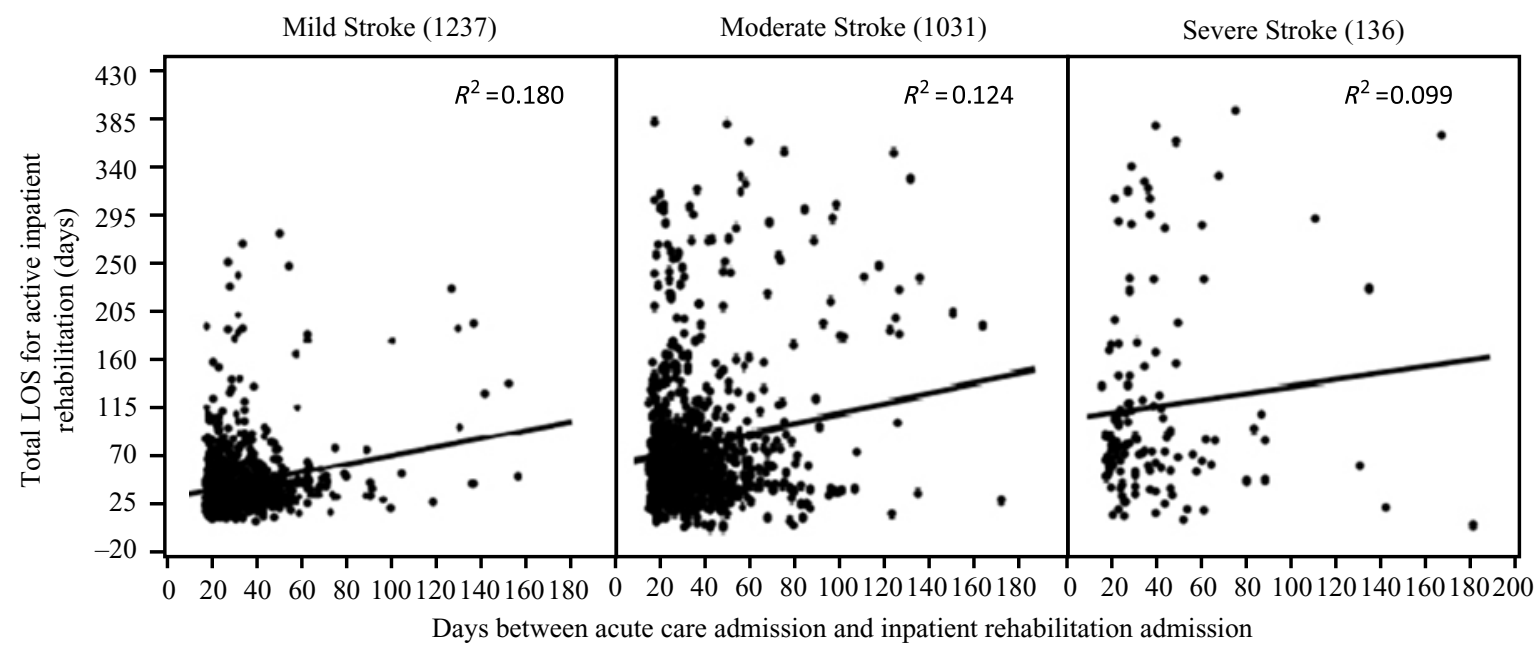

Figure 4: Scatter plots and trends illustrating relationships of LOS in inpatient rehabilitation and time to inpatient rehabilitation admission by impairment severity. The circles represent case numbers, and $R$-squared values $\left(R^{2}\right)$ represent the variance in LOS caused by time to inpatient rehabilitation admission. The lengths of stay and case numbers $(C N)$ of moderate stroke not shown in the scatter plot were 471 days (1413 CN), 482 days (1758 CN), 507 days (1275 CN), 533 days (1512 CN), 535 days (1823 CN), and 717 days $(2101 \mathrm{CN})$.

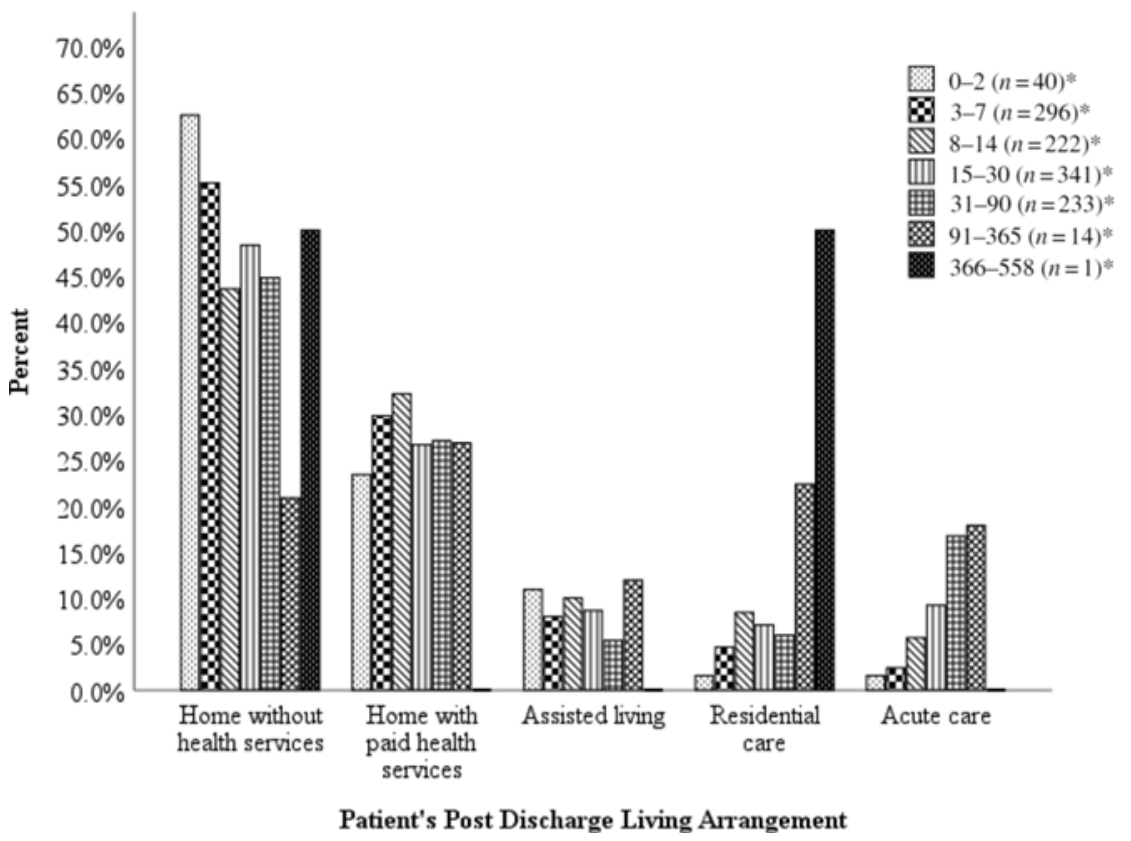

Figure 5: Bar charts of post-discharge living arrangement by groups of days between acute care admission and inpatient rehabilitation admission. The height of the bar represents percentage of cases that are likely to be discharged to the corresponding post-discharge living arrangement, and the color of the bar represents the group of days between acute care admission and inpatient rehabilitation admission. The asterisk * represents the number of cases that are likely to wait the corresponding number of days to be admitted to inpatient rehabilitation.

than the time reported in Ontario, which was considerably shorter at 15.9 days (9 median). ${ }^{18}$ The LOS in Alberta was also longer than in Ontario and other geographic regions with the overall mean LOS in Alberta of 65.6 days (mild stroke 41.3 days; moderate stroke 86.8 days; severe stroke 126.1 days). In Ontario, the overall mean LOS for active inpatient rehabilitation was 36.8 days (31 median); 47.4 days (42 median) in British Columbia; 53.0 days (44 median) in Saskatchewan and Manitoba; and 45.6 days (37 median) in Nova Scotia, Prince
Edward Island, New Brunswick, and Newfoundland and Labrador. $^{25}$ Regarding post-discharge living arrangements, there is a marked difference between stroke patients residing in Alberta and Ontario with the majority in Alberta returning home with no health services and the majority in Ontario returning home with paid health services. This difference in post-discharge health service access may be due to the length of time that stroke patients in Alberta spend in rehabilitation relative to those in Ontario. 


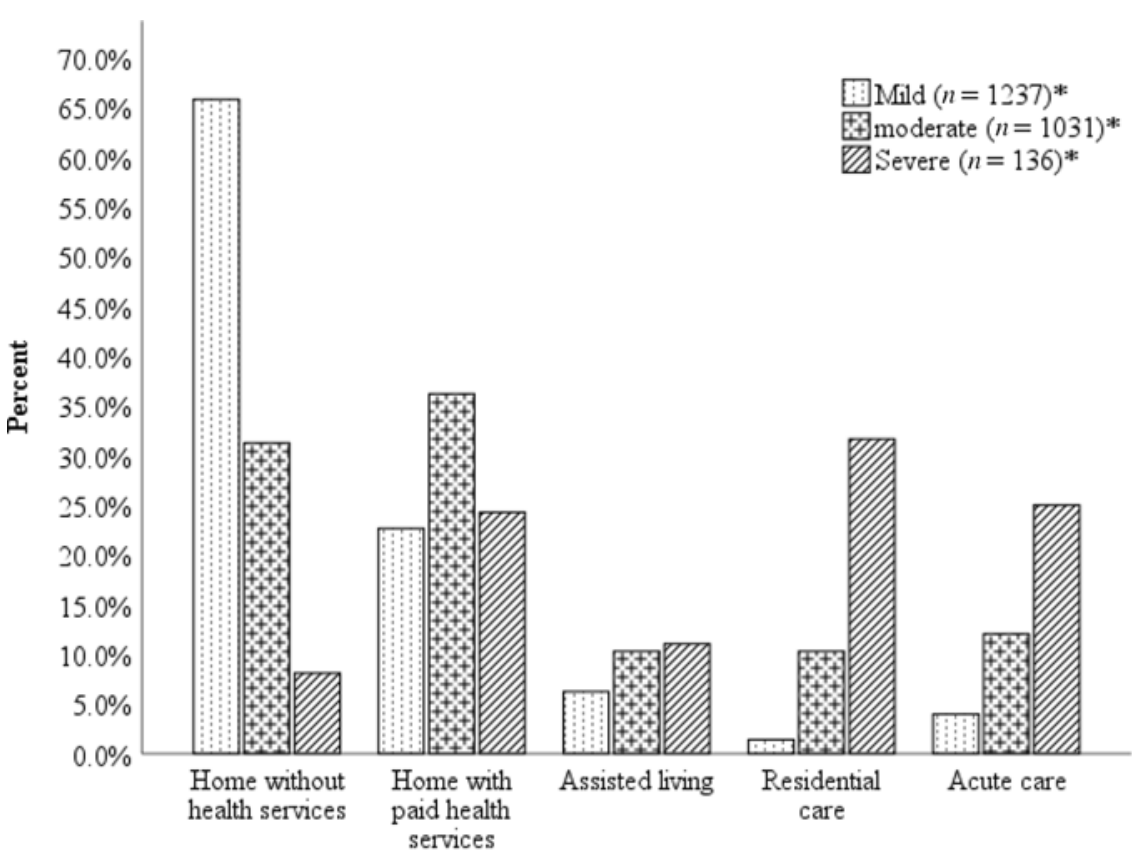

Patient's Post Discharge Living Arrangement

Figure 6: Bar charts of post-discharge living arrangement by category of functional impairment. The height of the bar represents percentage of cases that are likely to be discharged to the corresponding post-discharge living arrangement, and the color of the bar represents the category of functional impairment based on admission FIM score. The asterisk * represents the number of cases with the corresponding level of functional impairment.

Authors have suggested that a variety of factors can lead to delays in rehabilitation admission or longer LOS in rehabilitation. These include patients having medical complications (i.e., pneumonia or urinary tract infection) that tend to require more treatment time in acute care, or three medical tubes (i.e., tracheostomy, enteral feeding tube, and indwelling catheter) that have been associated with stroke patients staying 28 days longer in acute care and extending rehabilitation LOS by 20 days. $^{26}$ Patients' lack of motivation to participate and lack of family support are psychosocial factors that can also contribute to delays in admission to a stroke rehabilitation program. ${ }^{27}$ There is no reason to believe that stroke patients in Alberta are substantially different from those in other provinces with respect to these factors.

Slow times to rehabilitation admission and long LOS can also be associated with factors that are not patient related. Some of these factors include (a) discharge patterns and lack of post-acute care services to allow timely discharge or transfer to rehabilitation (e.g., lack of rehabilitation units, nursing homes, assisted living facilities, and home care services), (b) lack of insurance coverage, (c) lack of readiness to engage in rehabilitation program, ${ }^{28-30}$ (d) shortage of staff (e.g., nurses, occupational therapists, and physical therapists) in rehabilitation units, (e), poor communication and cooperation among health professionals and among rehabilitation units/facilities, (f) lack of public education regarding stroke symptoms and the seriousness of the disease, ${ }^{31}$ and $(\mathrm{g})$ socioeconomic characteristics (e.g., married, African American race, and younger age). ${ }^{29,17}$ Other non-patient-related factors that drive length of time to rehabilitation and LOS in Alberta system, in our opinion, are capacity issues and staff opinions around patients' readiness to return home or move on to the next phase of rehabilitation. Unlike the policy used in Ontario, Alberta does not have a similar policy for lengths of stay based on Rehabilitation Patient Group designations.

\section{Impact of Stroke Severity}

Stroke severity was linked to a number of the factors we explored. Severe stroke patients stayed longer in hospital but made functional gains similar to those of individuals with moderate stroke. Similar to a study by Ancheta et al. ${ }^{7}$ in New York State, we also identified that severe stroke patients were more likely to be discharged to long-term care facilities or back to acute care than those with moderate or mild stroke. FIM efficiency was generally poor for all stroke severity categories, suggesting that stroke patients experienced poor improvement in their functional abilities during each day of rehabilitation. Mild stroke patients had the greatest FIM efficiency ( 0.4 points/day) and were more likely to be discharged to home without paid services, compared to severe stroke patients who had the least FIM efficiency (0.2) and were more likely to be discharged to long-term care facilities or back to acute care. This finding was consistent with the literature that indicates that patients with greater FIM efficiency are more likely to be discharged to home from inpatient rehabilitation. ${ }^{21,32}$

Of particular interest, 1237 individuals with mild stroke were admitted to hospital, despite suggestions that individuals with mild stroke can be managed safely and effectively in the community. ${ }^{33}$ In an effort to support mild stroke patients, Alberta Health Services has an Early Supported Discharge Service that can provide in-home stroke rehabilitation for 1-2 h, 5 days/week in many parts of the province. Further exploration is needed to 
better understand why individuals with mild stroke continue to be routinely admitted to Alberta's rehabilitation beds.

\section{The Impact of Timing}

Though several authors have identified the importance of early access to rehabilitation on outcomes, ${ }^{6-8,17}$ the relationship we observed was more complicated. Length of time to rehabilitation admission was not significantly different between stroke severities. However, patients with moderate and severe stroke made significantly larger FIM gains than patients with mild stroke during inpatient rehabilitation, possibly due to the ceiling effect of FIM for mild stroke patients (13 patients with mild stroke had a FIM score of 126 at discharge from inpatient rehabilitation). As expected, LOS in rehabilitation was longer with increasing stroke severity. Time to rehabilitation admission had small, but significant impacts on functional gains and LOS. Patients with shorter times to rehabilitation admission and those with mild stroke were more likely to be discharged home without needing health services.

Factors associated with length of time to get into rehabilitation are multiple, and the observations of this study are unfortunately more likely related to process issues than the nature and severity of the stroke. Other jurisdictions such as Ontario (through the Ontario Stroke Network) have put rules in place to ensure that patients are moved expediently into inpatient rehabilitation. ${ }^{18}$ Processes such as this have yet to take hold in Alberta.

\section{Opportunities for Change}

This study has demonstrated that time since stroke influences rehabilitation LOS and FIM change. Stroke patients should be transferred to rehabilitation units early to shorten their LOS in rehabilitation and increase their physical and mobility function and performance of daily living activities. Mild stroke patients should be referred to Early Supported Discharge (ESD) services to reduce their LOS in acute care to decrease excessive costs.

\section{Limitations of This Study}

There were certain limitations to this study. The accuracy of FIM scores recorded by therapy staff and the individuals who enter information at each hospital in Alberta could be called into question. Further, a ceiling effect has been demonstrated for FIM Score $^{34}$ and has the potential to limit the ability to accurately measure patient improvement in the case of mild stroke patients. These data are from a single province that was also considered a limitation, but also provides unique contrast to other provinces such as Ontario where lengths of stay have been heavily influenced by provincial management of patient flow.

\section{Conclusions}

Our study provides a snapshot of inpatient stroke rehabilitation care in Alberta from 2013 to 2017. We evaluated whether there were differences in stroke rehabilitation outcomes (functional gains, LOS, discharge destination) based on stroke severity and whether the time from acute care admission to inpatient rehabilitation admission had an influence on these same outcomes. Despite suggestions that shortening the time to rehabilitation should improve outcomes, we observed only a small effect of timing on functional gains and rehabilitation LOS. Length of time to rehabilitation admission was not significantly different between stroke severities, and LOS was longer with increasing stroke severity. Individuals with moderate and severe stroke made significantly larger FIM gains than those with mild stroke during inpatient rehabilitation. Patients with shorter times to rehabilitation admission and those with mild stroke were more likely to be discharged home without needing health services.

\section{ACKNOWLedgements}

We acknowledge the help we received from Flora Stephenson, Janice Yajure, Natasha Mcguire, Agnes Lehman, and the entire DIMR Data Governance Team at Foothills Medical Centre who assisted us with data acquisition.

\section{Disclosures}

ET reports other from University of Calgary during the study period, and graduate studies scholarship and Dean's financial award for academic achievements outside the submitted work.

$\mathrm{KKS}, \mathrm{TG}$, and CS have no conflicts of interest to disclose.

SD reports other from Alberta Health Services during the conduct of the study; grants from CIHR, grants from Heart and Stroke Foundation, personal fees from Ipsen, personal fees from Merz, and personal fees from Roche, outside the submitted work.

\section{STATEMENT OF AUTHORSHIP}

ET contributed to the concept, design, data acquisition, data analysis, interpretation, and drafting of the manuscript.

KKS contributed to the design, data acquisition, data analysis, interpretation, supervision, critical reviews, and final approval of the manuscript.

TG contributed critical reviews for intellectual content and final approval of the manuscript.

CS contributed critical reviews for intellectual content and final approval of the manuscript.

SD contributed to the design, data acquisition, data analysis, interpretation, supervision, critical reviews, and final approval of the manuscript.

\section{REFERENCES}

1. Heart and Stroke Foundation. The 2014 stroke report; 2014.

2. Jeerakathil B, Thomson F, Hill M. The Alberta provincial stroke strategy: improving stroke care across Alberta. Interim evaluation report. Edmonton: Alberta Provincial Stroke Strategy. 2010.

3. Hebert D, Lindsay MP, McIntyre A, et al. Canadian stroke best practice recommendations: stroke rehabilitation practice guidelines, update 2015. Int J Stroke. 2016;11(4):459-84.

4. Scrutinio D, Monitillo V, Guida P, et al. Functional gain after inpatient stroke rehabilitation: correlates and impact on long-term survival. Stroke. 2015;46(10):2976-80.

5. Wang H, Camicia M, DiVita M, Mix J, Niewczyk P. Early inpatient rehabilitation admission and stroke patient outcomes. Am J Phys Med Rehabil. 2015;94(2):85-96.

6. Wang H, Camicia M, Terdiman J, Hung YY, Sandel ME. Time to inpatient rehabilitation hospital admission and functional outcomes of stroke patients. Phys Med Rehabil. 2011;3(4): 296-304.

7. Ancheta J, Husband M, Law D, Redding M. Initial functional independence measure score and interval post stroke help assess outcome, length of hospitalization, and quality of care. Neurorehabil Neural Repair. 2000;14(2):127-34. 
8. Maulden SA, Gassaway J, Horn SD, Smout RJ, DeJong G. Timing of initiation of rehabilitation after stroke. Arch Phys Med Rehabil. 2005;86(12):34-40.

9. Teasell R, Hussein N. Background concepts in stroke rehabilitation. The Evidence-based review of stroke rehabilitation. Available at: www.ebrsr.com; accessed July 4, 2019.

10. Horn SD, DeJong G, Smout RJ, Gassaway J, James R, Conroy B. Stroke rehabilitation patients, practice, and outcomes: is earlier and more aggressive therapy better? Arch Phys Med Rehabil. 2005;86(12):S101-14.

11. Hu MH, Hsu SS, Yip PK, Jeng JS, Wang YH. Early and intensive rehabilitation predicts good functional outcomes in patients admitted to the stroke intensive care unit. Disabil Rehabil. 2010;32(15):1251-59.

12. Huang HC, Chung KC, Lai DC, Sung SF. The impact of timing and dose of rehabilitation delivery on functional recovery of stroke patients. J Chin Med Assoc. 2009;72(5):257-64.

13. Kim WJ, Paik NJ. Optimal timing of rehabilitation: overview of the evidence in the literature. Brain Neurorehabil. 2012;5(1):1-5.

14. Massucci M, Perdon L, Agosti M, et al. Prognostic factors of activity limitation and discharge destination after stroke rehabilitation. Am J Phys Med Rehabil. 2006;85(12):963-70.

15. Paolucci S, Antonucci G, Grasso MG, et al. Functional outcome of ischemic and hemorrhagic stroke patients after inpatient rehabilitation: a matched comparison. Stroke. 2003;34(12):2861-65.

16. Paolucci S, Antonucci G, Grasso MG, et al. Early versus delayed inpatient stroke rehabilitation: a matched comparison conducted in Italy. Arch Phys Med Rehabil. 2000;81(6):695-700.

17. Salter K, Hartley BM, Foley NB. Impact of early vs delayed admission to rehabilitation on functional outcomes in persons with stroke. J Rehabil Med. 2006;38:113-17.

18. Hall RE, French E, Khan F, et al. Ontario stroke evaluation report 2016: a focus on stroke rehabilitation. Toronto, ON: Institute for Clinical Evaluative Sciences; 2016.

19. Teasell R, Foley N. Managing the stroke rehabilitation triage process. The Evidence-Based Review of Stroke Rehabilitation. 2008;1.

20. Stineman MG, Fiedler RC, Granger CV, Maislin G. Functional task benchmarks for stroke rehabilitation. Arch Phys Med Rehabil. 1998;79(5):497-504.

21. Ween JE, Alexander MP, D'esposito M, Roberts M. Factors predictive of stroke outcome in a rehabilitation setting. Neurology. 1996;47(2):388-92.

22. Graham JE, Granger CV, Karmarkar AM, Deutsch A, Niewczyk P, DiVita MA, Ottenbacher KJ. The uniform data system for medical rehabilitation: report of follow-up information on patients discharged from inpatient rehabilitation programs in 2002-2010. Am J Phys Med Rehabil. 2014;93(3):231-234

23. Heart and Stroke Foundation. Functional Independence Measure (FIM) evaluation summary; 2019.

24. Prodinger B, O'Connor RJ, Stucki G, Tennant A. Establishing score equivalence of the Functional Independence Measure motor scale and the Barthel Index, utilizing the International Classification of Functioning, Disability and Health and Rasch measurement theory. J Rehabil Med. 2017;49(5):416-22.

25. Grant $\mathrm{C}$, Goldsmith $\mathrm{CH}$, Anton HA. Inpatient stroke rehabilitation lengths of stay in Canada derived from the National Rehabilitation Reporting System, 2008 and 2009. Arch Phys Med Rehabil. 2014;95(1):74-8.

26. Roth EJ, Lovell L, Harvey RL, Bode RK, Heinemann AW. Stroke rehabilitation: indwelling urinary catheters, enteral feeding tubes, and tracheostomies are associated with resource use and functional outcomes. Stroke. 2002;33(7):1845-50.

27. Palmer S, Glass TA. Family function and stroke recovery: a review. Rehabil Psychol. 2003;48(4):255.

28. Hakkennes SJ, Brock K, Hill KD. Selection for inpatient rehabilitation after acute stroke: a systematic review of the literature. Arch Phys Med Rehabil. 2011;92(12):2057-70.

29. Roth EJ, Lovell L, Harvey RL, Bode RK. Delay in transfer to inpatient stroke rehabilitation: the role of acute hospital medical complications and stroke characteristics. Top Stroke Rehabil. 2007;14(1):57-64.

30. Willems D, Salter K, Meyer M, McClure A, Teasell R, Foley N. Determining the need for in-patient rehabilitation services poststroke: results from eight Ontario hospitals. Healthcare Policy. 2012;7(3):e105-18.

31. Gache K, Leleu H, Nitenberg G, Woimant F, Ferrua M, Minvielle E. Main barriers to effective implementation of stroke care pathways in France: a qualitative study. BMC Health Serv Res. 2014;14(1):95.

32. Bottemiller KL, Bieber PL, Basford JR, Harris M. FIM scores, FIM efficiency, and discharge disposition following inpatient stroke rehabilitation. Rehabilitation Nursing. 2006;31(1): $22-5$.

33. Teasell R, Hussein N, Foley N. Managing the stroke rehabilitation triage process. The Evidence-Based Review of Stroke Rehabilitation, 2008;1.

34. Kwon S, Hartzema AG, Duncan PW, Min-Lai S. Disability measures in stroke: relationship among the Barthel Index, the Functional Independence Measure, and the Modified Rankin Scale. Stroke. 2004;35(4):918-23. 